\title{
NUMERICAL SIMULATION HEAT TRANSFER IN THE SLAB TUNDISH
}

\section{INTRODUCTION}

The numerical modelling technique is successfully used for simulation of steel flow through the tundish [1-6]. Numerical programs used in simulation studies are not only furnished with modules designed for illustrating model liquid motion, but also enable the carrying out of heat exchange simulation [7-14]. The CFD (Computational Fluid Dynamic) method allows information on steel motion, flow, flow turbulence and steel temperature distribution in the tundish to be obtained. In the continuous steel casting process, where the tundish performs the function of a device batching steel to the mould, the monitoring of steel temperature is essential, which is closely related to the casting temperature of a particular steel grade. Numerical computation makes it possible to estimate the distribution of steel temperature fields within the facility to reveal the thermal state of the device. An ideal tundish should successfully protect flowing steel against the excessive loss of heat from the steel to the environment. The appropriate thermal insulation of the metal should be provided by refractory materials used for the construction of the tundish and insulating powders covering the liquid metal. The present article provides numerical computation results for the distribution of steel temperature in a tundish used for the casting of concast slabs in a Polish steel plant. The numerical computations were compared with measurements made under industrial conditions.

\section{CHARACTERIZATION OF THE TEST FACILITY AND TESTING METHODOLOGY}

Figure 1 shows the geometry of the tundish investigated of a nominal capacity of 30 tonnes. Steel flows to the tundish through a ceramic ladle shroud of a diameter of $70 \mathrm{~mm}$.

* M.Sc., ** D.Sc., Ph.D.: Faculty of Materials Technology and Applied Physics, Czestochowa University of Technology, Poland; cwudzinski@mim.pcz.czest.pl, jowsa@wip.pcz.pl 
The tundish incorporates a baffle with two overfall holes and a stopper rod system for controlling the outflow of steel to the mould.

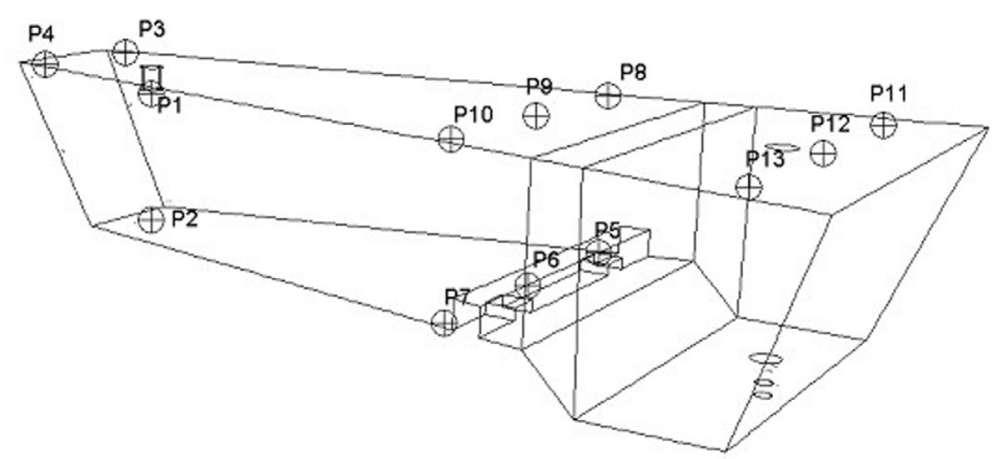

Fig. 1. Geometry of slab tundish and points of temperature measurement

Computer simulation of heat exchange was performed within the Fluent program. Numerical computations were made using the Bussinesq approximation defining the relationship between liquid steel density and metal temperature. The k- $\varepsilon$ model was applicable for turbulent flow. On the tundish inlet were assumed following initial boundary conditions for steel: velocity inlet $2,1 \mathrm{~m} / \mathrm{s}$ and turbulence intensity $5 \%$. Boundary conditions in the form of heat losses were assumed to be $-2600 \mathrm{~W} / \mathrm{m}^{2}$ on the tundish walls and bottom and $-15000 \mathrm{~W} / \mathrm{m}^{2}$ on the free surface, and $-1750 \mathrm{~W} / \mathrm{m}^{2}$ for the devices within the tundish, by using literature data provided in work [15-16]. The distribution of steel temperature fields in the tundish was simulated during the pouring of the tundish with two successively poured steelmaking ladles, each of a capacity of approx. 100 ton. It was assumed in the simulation that the temperature of steel flowing out from the first steelmaking ladle was $1829 \mathrm{~K}$ $\left(1556^{\circ} \mathrm{C}\right)$. This assumption was based on the measurement of steel temperature at the pouring of the first steelmaking ladle under industrial conditions, during which the temperature of the steel in the tundish was $1829 \mathrm{~K}$. This value was obtained from the measurement taken in the tundish pouring zone. The steel temperature in the tundish, as measured during the experiment, was lower by $10 \mathrm{~K}$ than the steel temperature measured prior to the departure of the first steelmaking ladle from the ladle treatment stand $1839 \mathrm{~K}$. Based on this result, the temperature of steel flowing out from the second steelmaking ladle was taken at 1825 $\left(1552^{\circ} \mathrm{C}\right)$ in the numerical simulation, because the temperature of steel in the steelmaking ladle, as measured during the experiment immediately prior to the ladle leaving the ladle treatment stand, was $1835 \mathrm{~K}$. Time of numerical simulation was such as real time of casting ladles during continuous casting slabs sequence. Figure 1 shows thirteen measurement points, at, which steel temperature was monitored during simulation. The points were situated in the tundish pouring and emptying zones and in the location of baffle installation. Additionally, the steel temperature was monitored at the tundish nozzle. In the vicinity of points 11 and 12, measurements of steel temperature were taken under industrial conditions, which allowed the verification of the numerical computations in respect of numerical result consistence with the industrial experiment. Thermal sensors supplied by Heraeus ElectroNite, used for experimental measurements, measured steel temperature at an accuracy of $\pm 2 \mathrm{~K}$. 


\section{COMPUTATION RESULTS}

As a result of numerical computations, steel temperature fields in the tundish were obtained. Figures 2 to 4 illustrate steel temperature fields in the selected planes of the tundish. Figures $2 \mathrm{a}, 3 \mathrm{a}$ and $4 \mathrm{a}$ represent temperature fields for non-stationary conditions during the flowing of steel at $1829 \mathrm{~K}$ to the tundish, whereas Figures $2 \mathrm{~b}, 3 \mathrm{~b}$ and $4 \mathrm{~b}$ illustrate temperature fields during the pouring of the tundish considered above with steel at a temperature of $1825 \mathrm{~K}$.

a)

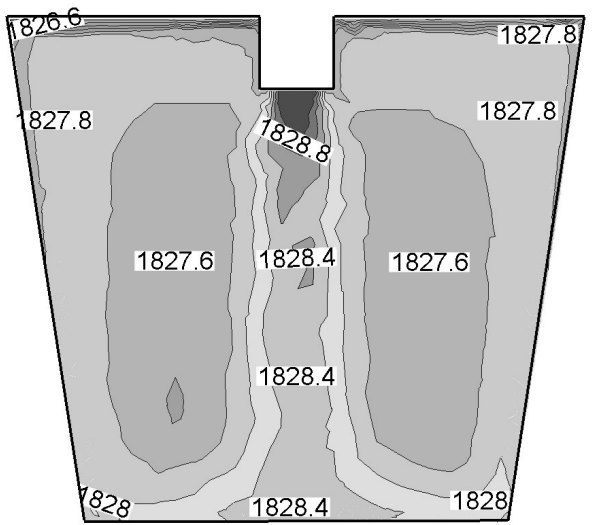

b)

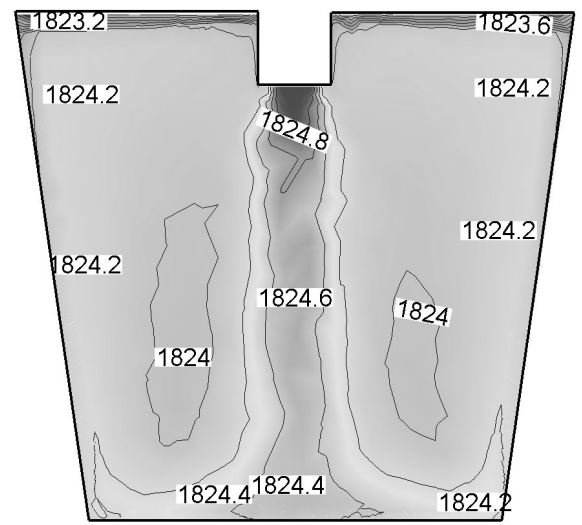

Fig.2. Field of steel temperature [K] in the pouring tundish zone-nonsteady time of simulation (time $=14,5 \mathrm{~min}$ ) for: first (a) and second (b) ladle in the continuous casting sequence

a)

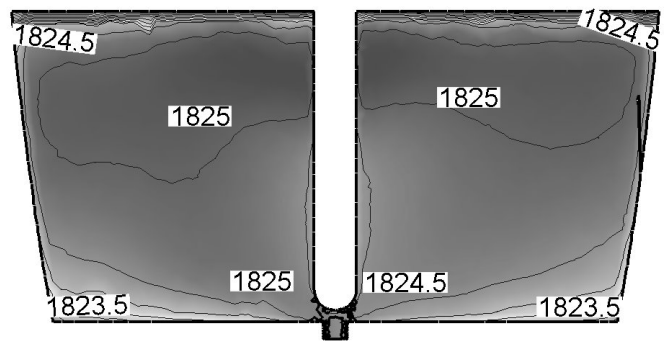

b)

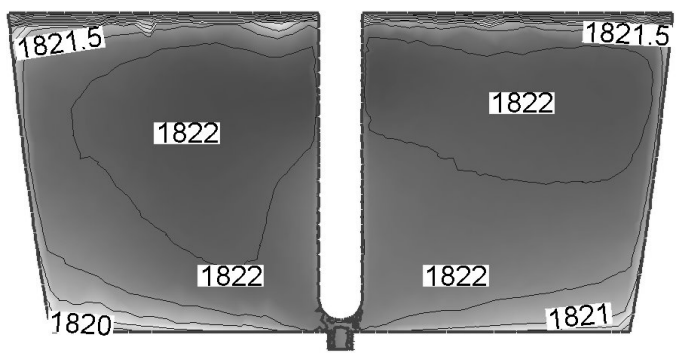

Fig.3. Field of steel temperature [K] in the tundish stoppers zone - nonsteady time of simulation (time $=14,5 \mathrm{~min}$ ) for first (a) and second (b) ladle in the continuous casting sequence 
When comparing the temperature fields in selected tundish zones, a moderate change in the distribution of the isotherms and a reduction of steel temperature in the tundish after starting the pouring of the second steelmaking ladle (Fig. $2 b, 3 b$ and $4 b$ ) by approx. four degrees in the tundish zones presented is observed.

a)

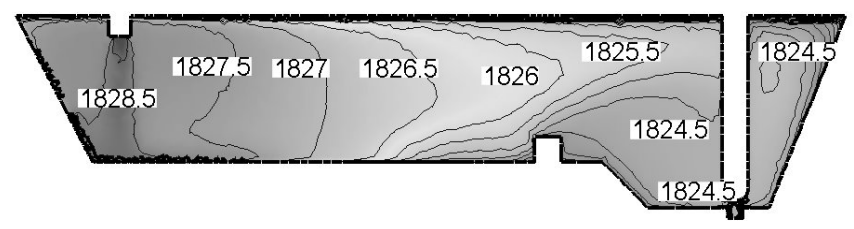

b)

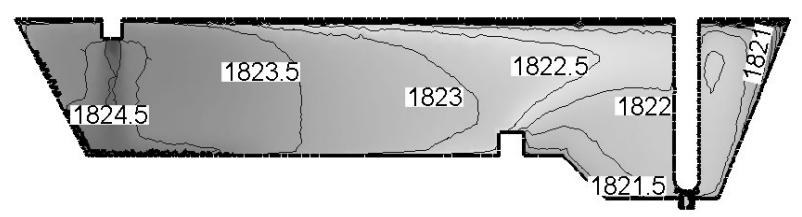

Fig.4. Field of steel temperature [K] in the longitudinal cross-section in the tundish - nonsteady time of simulation (time $=14,5 \mathrm{~min}$ ) for first (a) and second (b) ladle in the continuous casting sequence

Figures 5 and 6 represent the distribution of metal temperature at particular measurement points depending on the time of second ladle pouring. Figure 5a illustrates the effect of the constant-temperature stream supplying the tundish on the variation of steel temperature at point 2 that is located in the supplying stream axis, but is positioned below and in the immediate vicinity of the tundish bottom. At points 3 and 4, a similar character of temperature decrease was noted, which, at the end of the casting reaches the level of $4 \mathrm{~K}$ (Fig. 5b). Figures $5 \mathrm{c}, 5 \mathrm{~d}$ and $5 \mathrm{e}$ illustrate the distribution of steel temperature in the region of the baffle and the stopper rod system. The graphs shown in the above-mentioned figures indicate that the liquid steel has a higher temperature in the central tundish part compared to the steel temperature measured at the sidewalls. The arrangement of monitoring points in the tundish made it also possible to assess of to what extent the steel temperature field distribution is symmetrical to the central plane passing through the tundish gate and nozzle axes. The temperature characteristics shown in the figures indicate that the steel temperature varies in a similar way on either side of the tundish. The steel temperature measurements made under industrial conditions were compared with the numerical simulation results in the form of a diagram (Fig. 5e). The difference between the temperatures in the real facility and the virtual facility was $4.5 \mathrm{~K}$ as a maximum. The results obtained from the industrial experiment were not only burdened with an error in the form of the measuring inaccuracies of the probes used for the tests, but were also distorted by the temperature monitoring system, for which a tendency to increasing the temperature value by $3 \mathrm{~K}$ was found. Figure 6 shows the distribution of steel temperature at the tundish nozzle. It can be seen from this figure that the temperature decreases monotonically for the whole duration of the process and the maximum temperature drop is $4 \mathrm{~K}$ at the end of the process (after 41 minutes). 
a)

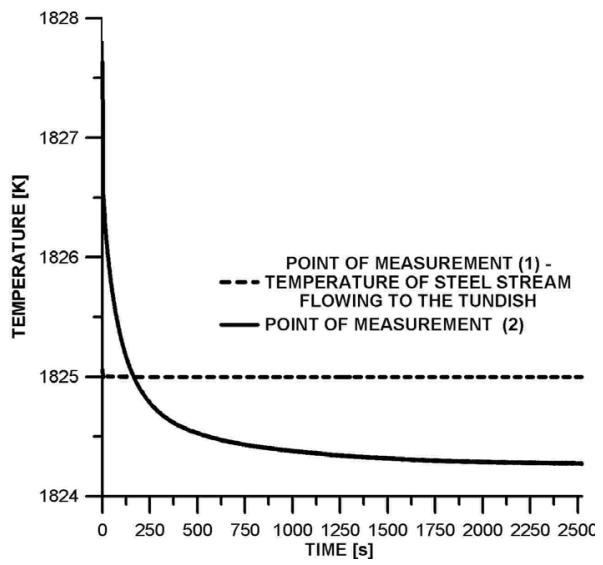

c)

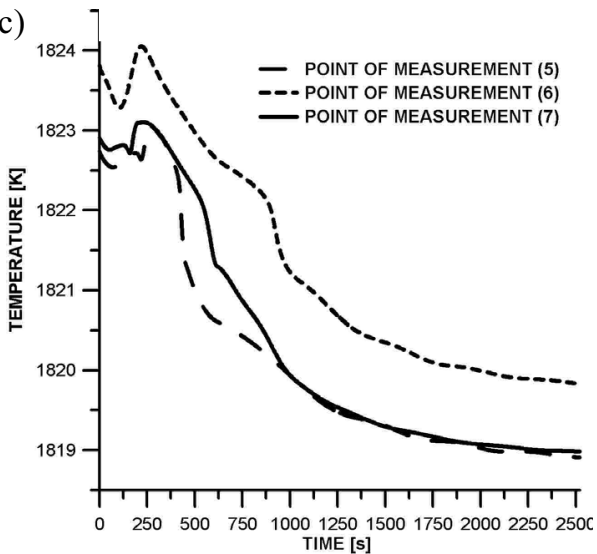

b)

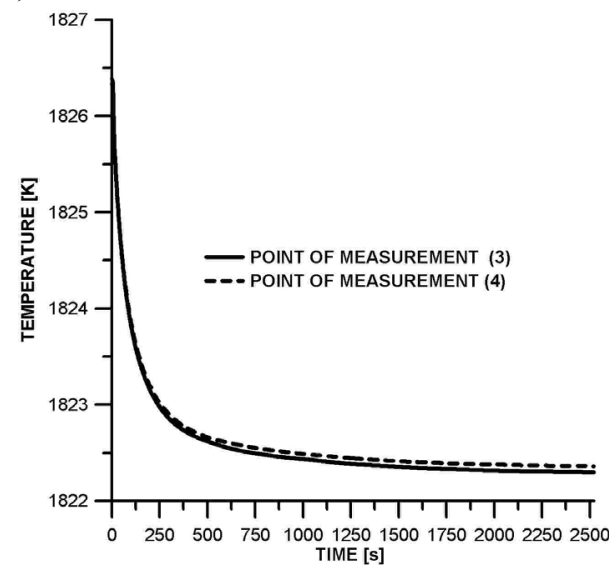

d)

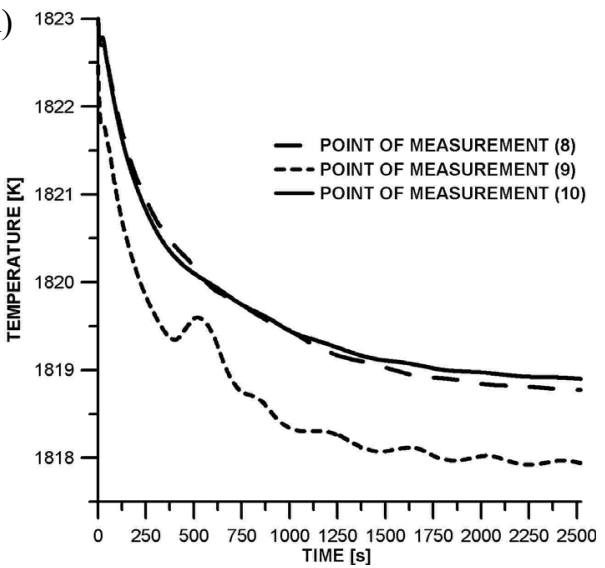

e)

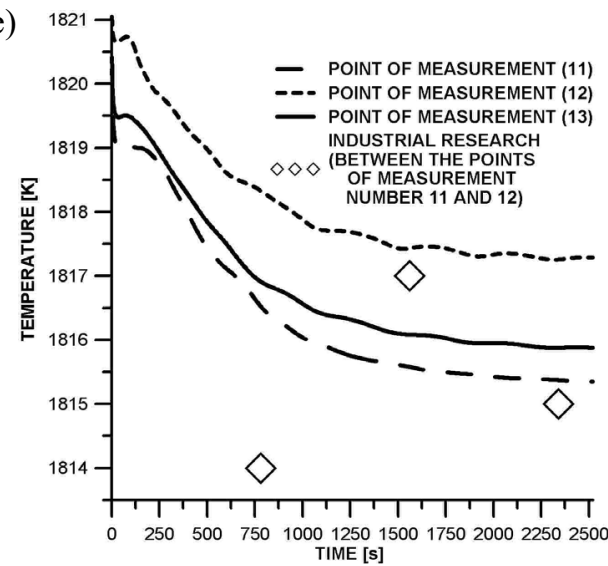

Fig.5. Distribution of temperature in the different points during steel flow from second ladle in the continuous casting sequence 


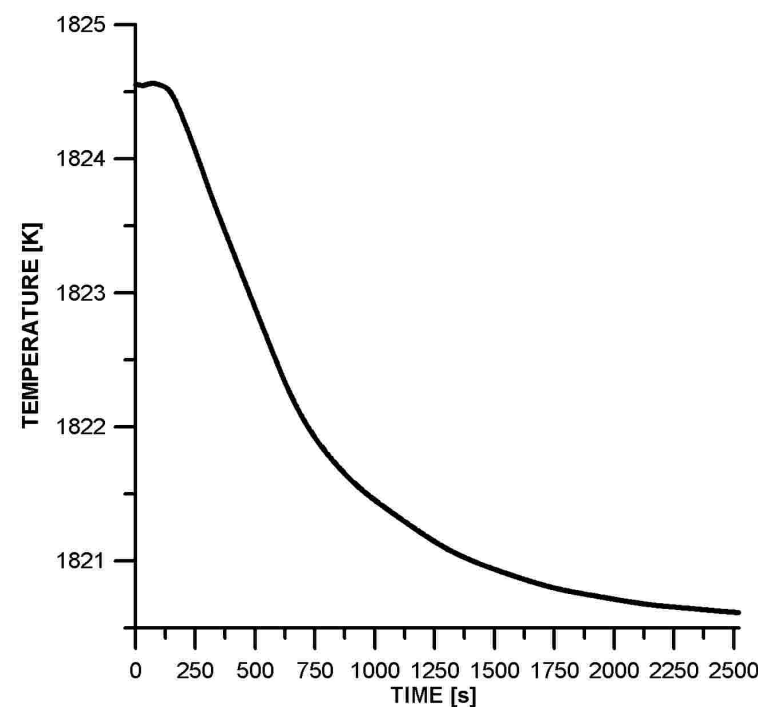

Fig.6. Distribution of temperature in the tundish inlet during steel flow from second ladle in the continuous casting sequence

\section{SUMMARY}

The mathematical model employed for numerical computation, despite the adopted simplifications in the form of a constant value of heat losses in particular planes (the tundish walls and bottom and the free metal table surface) and not allowing for the decrease in the temperature of steel flowing to the tundish, was subjected to industrial verification. Comparison of the industrial measurement and computation results showed a satisfactory agreement between the experiment and the simulation, so the applied numerical code could be successfully used for predicting the distribution of temperature fields in the tundish. The computations carried out indicate that the temperature of steel during the pouring of the second steelmaking has lowered by $4 \mathrm{~K}$, when taking the tundish nozzle as the point of measurement.

\section{Acknowledgements}

This scientific work has been financed from the resources allocated for science in the years 2007-2008 as Research Project No. N508 048 32/3441.

\section{REFERENCES}

[1] Barron-Meza M.A., Barreto-Sandoval J. de J., Morales R.D.: Metallurgical and Materials Trans. 31B, 2000, $63 \div 74$

[2] Solhed H., Jonsson L., Jonsson P.: Metallurgical and Materials Trans. 33B, 2002, 173 $\div 185$

[3] de Kock D.J., Craig K.J., Pretorius C.A.: 4th European Continuous Casting Conference, Birmingham, $2002,84 \div 93$ 
[4] Singh R.K., Paul A., Ray A.K.: Scandinavian Journal of Metallurgy 32, 2003, 137 $\div 146$

[5] Pys J., Valek L., Polach J., Mischinger T., Hascin J., Hons J., Malanik K., Rosypal F., Mayer F.: The Conf. Proc. Continuous Casting of Billets and Modelling of Steel Making Processes, Trinec, 2003, 359 $\div 367$

[6] Kumar A., Mazumdar D., Koria S.C.: Metallurgical and Materials Trans. 36B, 2005, 777 $\div 785$

[7] Ilegbusi O.J., Szekely J.: ISIJ International, Vol. 29, 1989, 1031 $\div 1039$

[8] Chakraborty S., Sahai Y.: ISIJ International, Vol. 31, 1991, 960 $\div 967$

[9] Chakraborty S., Sahai Y.: Metallurgical and Materials Trans. 23B, 1992, 135 $\div 151$

[10] Chakraborty S., Sahai Y.: Metallurgical and Materials Trans. 23B, 1992, 153 $\div 167$

[11] Chakraborty S., Sahai Y.: Ironmaking and Steelmaking, Vol. 19, 1992, 479 $\div 487$

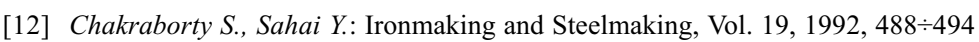

[13] Morales R.D., Lopez-Ramirez S., Barreto J. de J., Palafox-Ramos J.: 17th Process Technology Conference Proceedings, Orlando, 2000, 955 $\div 989$

[14] Lopez-Ramirez S., Barreto J. de J., Vite-Martinez P., Romero Serrano J.A., Duran-Valencia C.: Metallurgi-

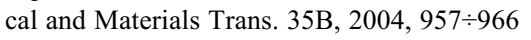

[15] Cwudziński A.: Materiały konf. IX Międzynarodowej Studenckiej Sesji Naukowej, Materiały i Technologie XXI wieku, Katowice 2007, 20 $\div 23$

[16] Cwudziński A.: Materiały konf. IX Międzynarodowej Studenckiej Sesji Naukowej, Materiały i Technologie

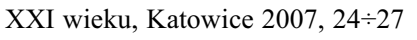

Received

September 2007 